\title{
La science sous observation - cent ans de mesure sur les scientifiques 1906 - 2006 Benoît Godin
}

Resenha - DOI: 10.3395/reciis.v2i1.161pt

\author{
Márcia de Oliveira Teixeira \\ Escola Politécnica de Saúde Joaquim Venâncio, Fiocruz, Rio de Janeiro, Brasil \\ marciat@fiocruz.br
}

O estímulo à pesquisa científica e ao desenvolvimento de novas tecnologias intensivas e com alta capacidade de aplicação no setor produtivo industrial tornou-se centro de um conjunto de ações do poder público e de debates na sociedade civil em muitos países. Todos os anos cifras vultosas são destinadas às instituições de pesquisa públicas e privadas, bem como às instituições de formação de novos pesquisadores. A despeito da diversidade de relações entre os sistemas público e privado de pesquisa e produção, das formas de governo e do arranjo político das sociedades a dinâmica em torno do processo de produção de conhecimentos técnico-científico é bastante similar.

Experimentamos no século XX um processo de homogeneização dos dispositivos de fomento à produção, da formação de pesquisadores e técnicos, da produção, circulação e divulgação desses conhecimentos. Processo que atingiu primeiro os países da Europa ocidental e os Estados Unidos da América, mas rapidamente disseminou-se por todo o ocidente e o oriente. Essa engrenagem complexa e gigantesca é acompanhada por estudos sobre a dinâmica e o estado das ciências e das tecnologias muitos dos quais associados ao campo de Estudos Sociais da Ciência e Tecnologia (ESCT).

No livro La science sous observation - cent ans de mesure sur les scientifiques 1906 - 2006, publicado em 2005, Benoît Godin oferece ao leitor uma análise densa dessa dinâmica, entretanto parte de uma dimensão pouco explorada - a medida da ciência. De fato, Benoît Godin, professor do Centre de Recherche in Urbanisation, Culture et Societê vinculado ao Institut National de la Recherche Scien-

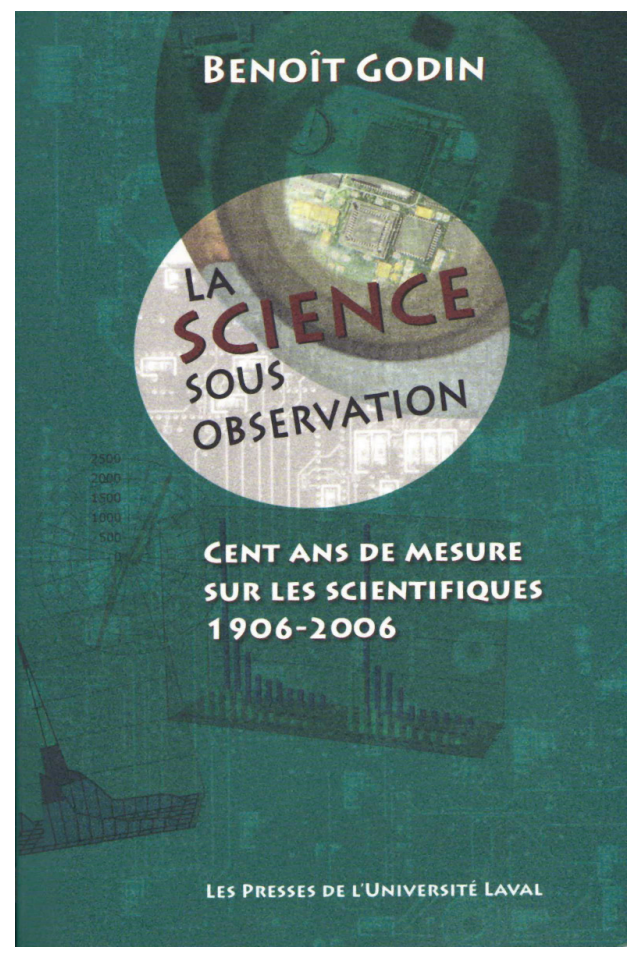
Quebec, Ed. Les Presses de L'Université Laval


tifique (INRS), especializou-se precisamente na análise crítica das estatísticas da ciência, tecnologia e inovação e em sua relação com as políticas públicas. Nos últimos sete anos, Benoît Godin publicou cerca de 40 artigos e dois livros (entre os quais La Science sous observation) sobre o tema, resgatando inclusive a história de seus precursores e dos principais organismos dedicados à elaboração de normas e à realização de estatísticas. Essa produção faz parte de um projeto, cuja amplitude me autoriza a tomálo como programa de pesquisa, intitulado "A Cultura dos Números", no qual a construção das estatísticas da ciência, tecnologia e inovação é analizada por intermédio de uma perspectiva sócio-histórica. O material utilizado em La science sous observation foi originalmente produzido para o Ciclo de Conferências da Maison des Sciences de L'Homme sob o título Mesurer la science: pour quoi faire? (Medir a ciência: porque fazer?) realizado em 2005. O livro mantém a estrutura proposta para as conferências, dividindo-se em torno de três temas: a construção das estatísticas da ciência; os usos das estatísticas; da ciência à inovação.

Antes de prosseguir considero importante dizer que o livro de Godin não faz um inventário analítico dos dispositivos técnicos utilizados pela estatística. Ele está interessado no processo de construção do objeto da estatística, parte constituinte do exercício de medição. Há no exercício da estatística um aspecto fundamental - sua capacidade de medição depende da produção de categorias e parâmetros capazes de definir e caracterizar o objeto a ser medido. Não é por outro motivo que as enquetes, os censos e as estatísticas de toda sorte geram manuais, nos quais a metodologia seguida é minuciosamente apresentada. Há preocupação em assegurar a cientificidade pelo rigor da disciplina metodológica. Mas em igual proporção a medição estatística precisa tornar evidente o seu objeto. Ela constrói o objeto da medição por meio de um exercício de categorização, ou melhor, a partir de uma taxonomia. Para além dos números em si, as estatísticas da ciência, da tecnologia e da inovação permitem analisar as diferentes categorias e conceitos relacionados a cada uma em diferentes períodos históricos; registros de arranjos sócio-técnicos entre a ciência, tecnologia e sociedade. Assim, o livro de Godin trata dos deslocamentos conceituais relacionados à ciência, à tecnologia e à inovação ao discorrer sobre as mudanças nos objetos (e em sua construção) e nas práticas de medição da ciência. Segundo ele há uma relação de coprodução entre os conceitos utilizados pela estatística e as concepções circulantes de ciência, tecnologia e inovação. Ou seja, os estatísticos não lançam mão de conceitos definidos alhures para construção de suas categorias; eles próprios participam ativamente da produção de novos conceitos e categorias, por conseguinte, de novos arranjos da ciência, tecnologia, inovação e sociedade. Nesse sentido, os estatísticos pensam e organizam a ciência, tecnologia, inovação e sociedade tanto quanto os economistas, sociólogos e cientistas dos mais variados campos.

Os arranjos sócio-técnicos e as diferenças na produção de conceitos evidenciam-se logo na primeira parte - os pioneiros. Nela encontramos uma leve e instigante narrativa sobre os pioneiros da medição da ciência - o suíço Alphonse de Candoll (1873), o britânico Francis GALTON (1874) e o americano James Mckeen CATTELL (1906) - dedicando especial atenção aos dois últimos. A medição realizada pelos pioneiros concentra-se no pesquisador. Todavia, a despeito do curto intervalo que separa os trabalhos de Galton e Cattell, já é possível identificar sutis mudanças. Em Galton o foco está inteiramente centrado nos cientistas, na sua formação, na opção pela carreira científica cuja motivação é o gosto pela ciência. Entre as variáveis propostas e analisadas por Galton encontramos a escolaridade, as motivações para ser pesquisador e o papel da família. Embora sua análise tenha uma forte inspiração das concepções eugenistas, é curioso observar que alguns temas reaparecem em estudos contemporâneos de carreira científica.

James Cattell, por sua vez, parte de um repertório totalmente novo, começando pela origem de seu primeiro trabalho (American Men of Science). O repertório biográfico sobre cientistas americanos surge da iniciativa de uma instituição filantrópica de distribuir subvenções a pesquisadores. $\mathrm{O}$ intuito do repertório biográfico era auxiliar a escolha dos pesquisadores. Considero essa história de origem emblemática de todo o trabalho ulterior de Cattell, bem como dos muitos usos atribuídos às estatísticas da ciência ao longo do século XX. Porque nessa origem há um embrião da associação contemporânea das estatísticas primeiro com a política de ciência e tecnologia, segundo com a tomada de decisão. Adiante retomarei esse dois pontos, apenas antecipo que a análise de Benoît Godin contribui para desconstruir o uso da estatística (ou sua redução) como base para a tomada de decisão. Por hora, quero frisar um deslocamento entre a medida da ciência com base no número dos homens de gênio dedicados ao conhecimento científico (Galton), para uma baseada na qualidade e na quantidade da performance dos cientistas (Cattell). O trabalho de James Cattell não perde o foco na figura emblemática do cientista, porém Godin destaca como no seu "repertório" já há uma sutil preocupação com o que os cientistas fazem e com onde eles fazem (em termos geográficos). Nesse sentido, Cattell manifesta uma acurada percepção das potenciais relações entre ciência, tecnologia e o mundo produtivo norte-americano. Alias Godin também destaca o fato de James Cattell ser o primeiro a estimar o valor econômico de "um homem de ciência", utilizando para tanto o salário (GODIN, 2005: 12). O trabalho de James Cattell e outras iniciativas sinalizadas por Benoît Godin emergem em um contexto favorável ao desenvolvimento de percepções da ciência como "atividade" próxima ao mundo produtivo industrial; distante, por conseguinte, da concepção de ciência como uma manifestação de gênio individual. É sintomático, assim, que o National Research Council divulgue em 1920 (15 anos após a publicação do estudo de Cattell) a primeira edição do repertório sobre os laboratórios industriais americanos (GODIN, 2005: 20).

Gostaria de complementar, antes de finalizar os comentários à parte dedicada aos pioneiros, com duas observações. Cattell, a exemplo de todo uma geração posterior de estatísticos da ciência, foi antes de tudo alguém 
preocupado em refletir sobre as relações entre a ciência e a sociedade norte-americana de seu tempo. Benoît Godin conclui suas observações sobre Cattell colocando-o como "origem do que se convencionou chamar de cientometria" (GODIN, 2005: 12). Em segundo lugar, Cattell aponta para uma concentração geográfica na formação de pesquisadores e apela para a necessidade de adotar medidas para a sua desconcentração. A concentração geográfica de cientistas e instituições de ciência e tecnologia é uma questão válida para pensarmos a ciência na contemporaneidade, com inúmeros desdobramentos para o campo de Estudos Sociais da Ciência e Tecnologia; com o qual identifico a produção acadêmica de Benoît Godin. Em países como Brasil onde as diferenças regionais são intensas, a desconcentração é alvo de políticas públicas nas últimas três décadas. Porém, a dinâmica mundial do sistema de produção e circulação dos conhecimentos técnico-científicos aprofunda essa concentração. Entre outros fatores, destaco: a) a alta tecnificação da ciência que dificulta o acesso aos equipamentos e as técnicas consideradas de última geração pelos laboratórios localizados fora dos centros mais dinâmicos de produção de conhecimento; b) os critérios utilizados para a concessão de financiamentos que privilegiam os índices de publicação e citação, dificultando o acesso de grupos de pesquisa novos; c) a concentração de instituições formadoras de pesquisadores em determinados países, facilitando o fluxo de jovens pesquisadores e sua fixação nessas instituições.

Nos 1930 anos que separam as décadas de 1920 e 1950 do século XX a estatística da ciência tornou-se um elemento fundamental nos escritos acadêmicos sobre a ciência e tecnologia. A partir da década de 1950 as enquetes estatísticas adquiriram regularidade. Na década de 1960, por sua vez, temos o inicio da confecção e difusão dos manuais de metodologia para enquête de grande envergadura, a exemplo do Manual Frascati produzindo pela Organisation for Economic Co-Operation and Development (OCDE) em 1962. Essa movimentação está relacionada com a posição da ciência e da tecnologia junto aos governos nacionais e ao setor produtivo público e privado. Nesse período, a ciência e a tecnologia tornaram-se alvos permanentes de políticas públicas. É a fase de criação, institucionalização e crescimento das agencias e organismos dedicados à produção de estatísticas da ciência, ao fomento à pesquisa, bem como à produção de estudos e relatórios técnicos governamentais sobre as atividades de ciência e tecnologia. Cabe salientar como no pós-guerra ocorre a constituição de organismos internacionais cujas estatísticas influenciam instituições localizadas em diferentes países, além das políticas públicas para a ciência e tecnologia em diferentes contextos sócio-político-econômicos ao longo das últimas quatro décadas do século XX. No Brasil, por exemplo, data dos anos 1950 a criação do Conselho Nacional de Pesquisa (CNPq), principal agência de fomento à ciência e tecnologia. Em geral, identificamos a homogeneização de políticas e concepções de ciência e tecnologia precisamente com a emergência dessas organizações internacionais. Porém, para os cientistas sociais, particularmente aqueles comprometidos com os Estudos Sociais da Ciência e Tecnologia, o ponto é indagar como esse processo (de homogeneização) se instaura e se reproduz. Benoît Godin observa como a disseminação das estatísticas de ciência e tecnologia desempenhou uma posição ativa no processo de homogeneização. Posição que se deve a prática de definição precisa de metodologias de coleta e de análise dos dados, as quais envolvem antes de qualquer enquête a conceituação do que será medido. Por conseguinte, essa posição está diretamente relacionada à produção e à disseminação mundial dos manuais entre os quais se destacam o Frascati, Oslo, além dos produzido por organizações como National Science Foudation (NFS) a partir da década de 1950.

Godin observa como a posição política das estatísticas da ciência é sempre associada ao apoio à tomada de decisão pelos governos e pelas agências internacionais. Assim, invariavelmente, ele também observa, as estatísticas assumem uma posição coadjuvante e neutra. Ou seja, coletam e sistematizam dados sobre um determinado campo de atividade, o qual a partir de um momento histórico adquiriu valor político-econômico alto; porém, a estatística em si não guarda relação alguma com a produção desse valor. As políticas públicas fazem uso da estatística, mas a estatística e os estatísticos não fazem política. Benoît Godin procura exatamente salientar a política dos números, àquela presente na prática estatística, desfazendo sua áurea de neutralidade. O estatístico é um ator político, uma vez que a estatística participa ativamente do processo de tomada de decisão. Novamente o ponto para os pesquisadores influenciados pelos Estudos Sociais da Ciência e Tecnologia é saber como isso ocorre? Para Godin, essa participação ocorre fundamentalmente de duas formas: com as instituições encarregadas das estatísticas da ciência decidindo o que será medido; com essas mesmas instituições conceituando o que será medido. Nos dois casos trata-se de uma atividade de ordenamento; a conceituação, em especial, é uma forma de ordenamento. Ao circunscrever o alvo, definir como a medida será realizada e qual categorização será adotada, a enquête estatística estabelece e baseia sua ação prática em um determinado padrão. Godin lembra como a economia do conhecimento, e nos últimos anos, a economia da inovação fornecem o quadro conceitual das estatísticas da ciência (GODIN, 2005: 5). A economia da inovação ilustra bem o tipo de dinâmica que Benoît Godin deseja analisar em suas pesquisas sobre a estatística. A economia da inovação produziu um quadro de referencia muito bem acabado para as atividades de pesquisa e desenvolvimento, para as relações entre pesquisa e o setor produtivo, além de propostas de financiamento público às instituições inovadoras. A estatística auxiliou na disseminação desse quadro ao fornecer dados. A proposição de Godin, em torno da qual estrutura sua história das estatísticas da ciência, é que elas participaram do processo de ordenamento da ciência e da tecnologia contemporânea, enquanto supostamente limitavam-se a registrar seus números. E participaram exatamente ao medirem sua atividade 
quantitativa e qualitativamente. Benoît Godin fornece uma série de exemplos para sustentar sua proposição, no entanto irei concentrar-me naquele que considero o melhor aspecto - a análise de como as estatísticas participaram dos deslocamentos de sentido entre ciência e pesquisa; da pesquisa para o binômio básica e aplicada, acrescentaram o desenvolvimento e, mais recentemente, a inovação. Evidentemente foge aos propósitos de uma resenha reproduzir a riqueza de detalhes que cercam a descrição de Godin desses deslocamentos de sentidos e constituição de novas categorias. Entretanto, considero importante chamar a atenção do futuro leitor de La science sous observation para alguns pontos que mobilizam esses deslocamentos.

O primeiro grande deslocamento ocorre quando o objeto a ser medido pela enquête estatística não é mais $o$ cientista e sim as atividades de pesquisa. Esse deslocamento produz em um primeiro momento a categoria de pesquisa. Assim, "a concepção oficial de ciência veiculada pelas estatísticas sobre a ciência repousa em uma definição centrada na pesquisa" (GODIN, 2005: 15). A atividade de pesquisa reforça a concepção de que não estamos lidando e, portanto, medindo uma atividade diletante de produção de conhecimento; mas um empreendimento organizado e sistemático de produção de conhecimentos por meio de determinados parâmetros e realizada em instituições organizadas segundo um padrão especifico. O caráter e a intensidade dessa sistemática adquirirão uma importância enorme nas enquêtes estatísticas. A definição se uma atividade é ou não sistemática é crucial, por exemplo, para determinar se uma empresa industrial faz ou não pesquisa. Cabe salientar como o deslocamento de sentidos e a definição de categorias ocorrem simultaneamente à emergência da gestão científica ou da planificação das atividades científicas (GODIN, 2005: 16). Emergência, por conseguinte, de um conjunto de ações governamentais orientadas para a articulação do financiamento, da formação de quadros e da priorização de áreas de pesquisa. Logo as estatísticas e suas metodologias compunham um grande esforço de demarcar os limites da pesquisa e em decorrência enumerar as instituições de pesquisa, alvos prioritários da política científica empreendida por organismos governamentais e internacionais.

A produção de dados mais precisos pelas enquêtes estatísticas sobre a atividade de pesquisa implicava na qualificação dessa atividade; além de considerar sua sistematicidade. Enquetes mais amplas dependem de definições e caracterizações do que efetivamente se faz de forma mais precisas. Assim, segundo Godin devemos a NFS e a OCDE o uso de uma série de atividades para definir mais apropriadamente o que estava compreendido sob a macro categoria da pesquisa científica: pesquisa fundamental, aplicada, engenharia, testagem, prototipagem. Quase imediatamente, as quatro últimas formaram o que designamos atualmente como desenvolvimento (GODIN, 2005: 21). A NFS e a OCDE não cunharam essas categorias. Godin lembra como pesquisa fundamental, pesquisa de base, pesquisa aplicada e desenvolvimento já figuravam em reflexões acadêmicas sobre ciência desde a década 1930. Como exemplo cita a produção de John Bernal (GODIN, 2005: 21). Esse desdobramento não resultou em enquetes sobre cada atividade. A intenção, em grande parte, era separar os alvos, ou seja, caracterizar melhor as atividades realizadas no âmbito dos laboratórios industriais, as quais suscitaram inúmeras duvidas e discussões em levantamentos feitos antes da década de 1950. A hoje clássica divisão entre pesquisa fundamental (ou básica), aplicada e desenvolvimento aparecerá no quadro elaborado para uma enquête sobre a pesquisa industrial nos Estados Unidos da América em 1953. O quadro foi inspirado no trabalho de R.N. Anthony (DEARBON et al., 1953). Esse ponto é instigante, porque as enquêtes para o setor industrial sempre ocuparam parte das discussões metodológicas das estatísticas da ciência. Em países como Brasil, nos quais a pesquisa industrial concentra-se em pouquíssimas empresas públicas, cabe aos pesquisadores indagar quais são os dilemas metodológicos das estatísticas da ciência?

Porém, o destaque ao desenvolvimento surge pouco depois, já na década de 1960. O trabalho de R.N. Anthony teve grande influencia, bem como a intensificação das relações entre estatísticos da ciência e economistas. Para Benoît Godin não se compreenderá o peso da categoria desenvolvimento, posteriormente a de inovação, sem considerar a origem industrial de ambos. E há mais envolvidos aqui. Há um deslocamento importante das estatísticas e das políticas de ciência e tecnologia nesse movimento. Um deslocamento que aponta para a medição da capacidade de gerar e produzir novos produtos e processos. Desenvolvimento deveria assim aglutinar atividades especificas para esses propósitos, tais como a engenharia, o design e a prototipagem. Ao analisar a emergência do desenvolvimento nas enquêtes e nos modelos explicativos da ciência a partir da década de 1960, Godin retoma a posição da estatística na produção do mundo contemporâneo ou das relações ciência, tecnologia, inovação e sociedade. Em relação ao modelo linear, alvo nos últimos 20 anos de acaloradas contestações, ele observa que o “(..) modelo foi em parte construído graças aos estatísticos. São os industriais e os pesquisadores das escolas de gestão, mas também os indivíduos e organismos que se lançam ao exercício de medir com uma taxonomia baseada nesses três termos, que formalizam o modelo. Contrariamente ao que reporta a literatura, o modelo linear não provém de V BUSH (1945)" (GODIN, 2005: 26). Ele considera que as bases do modelo linear repousam no trabalho de pesquisadores em gestão e economistas que buscavam aprimorar categorias e a própria compreensão sobre a ciência para analisarem as empresas com ênfase no mercado. Para tanto, foram influenciados pelas propostas de R. N. Anthony (DEARBON et al., 1953).

A inovação é uma construção mais recente, muito embora desde os anos 1950 utilize-se o termo. Mas inovação como categoria emergente nas análises de ciência e tecnologia e nas estatísticas de ciência é um fenômeno da década de 1990, portanto um evento do fim de século. Considero esse evento como efeito dos estudos sobre a nova economia, nos quais as ciências e as tecnologias 
emergem como sustentáculos e elementos dinamizadores da moderna produção de valor. Creio que essa afirmação encontra uma boa acolhida nos argumentos de Benoît Godin, sobretudo no capítulo dedicado aos usos da estatística (GODIN, 2005: 54 a 62). O quadro conceitual da nova economia, no qual as biotecnologias e as tecnologias da informação desempenham uma posição preponderante, tem uma grande influencia no desenho das estatísticas da ciência. Porém, em contrapartida, as estatísticas são essenciais para a construção da idéia de uma nova economia intensiva no uso e na produção de conhecimentos técnico-científicos. Em La science sous observation encontramos vários exemplos de como essa co-produção ocorre. Os economistas utilizam extensamente dados estatísticos e lançam mão de argumentos baseados na retórica gráfica, em geral, retirada de enquêtes estatísticas. As análises também capturam largamente categorias produzidas e aperfeiçoadas por estatísticos e economistas que trabalhavam em organismos dedicados à estatística.

A emergência da inovação marca um novo deslocamento. A inovação não é um produto ou resultado, mas processo que envolve um conjunto complexo de atividades para gerar um produto ou processo. Essa definição figura em 1967 no Relatório Steacie do Departamento de Comércio Norte-americano (US DEPARTMENT OF COMMERCE, 1967). Algumas hipóteses ajudam a compreender esse deslocamento e a rápida disseminação da categoria inovação junto aos estatísticos e pesquisadores da ciência. Segundo Godin para compreendermos esse deslocamento é preciso considerar a posição política da inovação e sua vinculação instantânea com a produção industrial. Ou seja, a inovação enfatiza o universo produtivo do setor industrial, as trocas comerciais e seus dispositivos, o valor de mercado. Uma invenção torna-se uma inovação quando (e apenas se) ela encontra um mercado e um valor de troca. Mas qual é a diferença em relação a categoria de desenvolvimento? Porque é possível tomar os deslocamentos ulteriores entre ciência - pesquisa - desenvolvimento como arranjos para as relações entre ciência, tecnologia e sociedade com ênfase na posição do setor industrial. Entretanto há uma diferença sutil. Talvez pela primeira vez a compreensão da ciência e da tecnologia foi descentrada da pesquisa realizada nas instituições acadêmicas. E o esforço dos estatísticos para apreender a pesquisa realizada nos laboratórios industriais é um elemento importante, senão fundamental, na produção da categoria de inovação. É importante observar que esse esforço está na raiz das estatísticas da ciência tal qual as conhecemos hoje. A categoria de inovação é um efeito emergente do processo de valorização social das atividades realizadas em espaços determinados, bem como de uma questão de ordem prático-conceitual: como medir essas atividades e simultaneamente preservar sua singularidade? As reflexões de Benoît Godin nos levam a indagar como os estatísticos participaram desse processo de valorização ao perseguirem a medida da inovação. Porque ao fazê-lo, estabeleceram suas singularidades, produziram conceitos, firmaram parâmetros. Ao final, participaram do processo de demarcar fronteiras entre o desenvolvimento e a inovação.
Benoît Godin chama atenção para a baixíssima relação entre as estatísticas da ciência e outros levantamentos sociais. No Brasil, por exemplo, as estatísticas da ciência em geral são apresentadas em relação com o produto interno bruto, série histórica de investimentos com P\&D e em pouquíssimos casos com dados sobre a escolaridade, o acesso aos serviços de saúde e ao saneamento básico. Considero esse dado instigante quando analisamos o discurso da inovação, amplamente baseado na sua relação com o aumento qualitativo e quantitativo da produção, com o crescimento econômico e com o nível de desenvolvimento dos países. A medida da ciência e da tecnologia adquire valor no bojo da intensificação da equivalência entre a produção científica e seus impactos econômicos na sociedade. Para Benoît Godin a estatística experimentou desde o final do século XIX um deslocamento acelerado entre uma prática "destinada a participar dos avanços da ciência" para um comprometimento com "a planificação da ciência para fins contábeis e econômicos” (GODIN, 2005: 76). Em uma palavra, as estatísticas passaram do foco centrado na produção da ciência para um outro que valoriza a produtividade, entendida em sua dimensão econômica. Isso explica o descolamento entre as estatísticas da ciência e outras estatísticas sociais. Todavia, quando se relaciona a inovação com o nível de desenvolvimento de um país esse distanciamento (entre as enquetes da ciência e as demais) torna-se uma questão instigante para os Estudos Sociais da Ciência e Tecnologia. Ao menos deveria torna-se, na medida em que podemos problematizar qual é o alvo da medida? Porque caso não se aproximem de outras medições sociais, as estatísticas da ciência não dimensionam a dinâmica das relações entre inovação, tamanho da economia e dados sociais referentes à escolaridade básica (e não apenas de pós-graduação), acesso a saúde, saneamento, habitação e índices de violência.

Por fim, a leitura do trabalho de Benoît Godin nos instiga a olhar para as nossas próprias estatísticas da ciência, tecnologia e inovação. O Brasil ensaia a disseminação de uma concepção de gestão da ciência e tecnologia focada na produtividade. Concepção diversa da que estruturou e ainda opera parte da estrutura organizacional das principais instituições de pesquisa do país. A presença de laboratórios industriais no Brasil é restrita a alguns setores, sendo os mais ativos (petróleo e agrícola) vinculados ao setor público. Isso por si só demarca diferenças com os contextos descritos por Benoît Godin. Logo chamo atenção para a necessidade dos cientistas sociais indagarem qual o suporte sóciopolítico dessas categorias e para as concepções de ciência, tecnologia e sociedade que lhes são correlatas? Um dos maiores méritos do trabalho de Benoît Godin (nesse e em outros livros) é sistematizar dados que materializam o processo de produção sóciopolítica das atividades de pesquisa, desenvolvimento e inovação, bem como das categorias que as descrevem. As atividades e as categorias não estão descoladas de um universo de práticas econômicas, políticas e um determinado ordenamento legal. Trata-se de uma produção que ocorre em um único, denso e turbulento fluxo do qual emergem as 
sociedades contemporâneas baseadas na economia de mercado capitalista e nos valores sócio-educacionais e morais judaico-cristãos. Trata-se, em última instância, de enfrentar um problema de transposição - transposição de modelos de produção de conhecimento técnico-científico, transposição de modelos de medição e transposição de relações entre ciência, tecnologia e sociedade.

Por outro lado, a produção local de estatísticas sobre a ciência é relativamente recente e muito influenciada pelos manuais internacionais e pelas grandes instituições produtoras de dados, como a NFS e a OCDE. Isso a despeito do esforço de países latino-americanos de produzirem um manual próprio, capaz de apreender as especificidades e dificuldades metodológicas desses países (Manual de Bogotá). Novamente cabe aos cientistas sociais interessados no campo Ciência, Tecnologia e Sociedade indagarem qual a viabilidade desse esforço? Temos países com realidades sociais, políticas, econômicas e jurídicas diversas. Por outro lado, os manuais internacionais participam do processo de globalização da produção e da medida da produção de C\&T\&I. Qual a posição política de tentativas como o Manual de Bogotá na produção de um modelo de produção e medida da produção de C\&T\&I hegemônico em países latino-americanos? Considero, assim, como tarefa dos historiadores e sociólogos aceitarmos o convite de Benoît Godin e analisarmos como essas diferenças influenciam a apropriação dos Manuais, a produção autóctone de manuais e o exercício da estatística entre nós.

\section{Referencias bibliográficas}

BUSH, V. 1945. Science: the endless frontier. North Stratford. Ayer Co. 1995.

CATTELL, J. M. American Men of Science: a biografhical directory. New York: The Science Press. 1906.

DEARBON, D.C.; KNEZNEK, R.W; ANTONY, R.N. Spending for Industrial Research, 1951 - 1952. Division of Research. Graduate School of Business Administration. Harvard University. 1953.

GALTON, F. English men of science: the nature and nurture. London: Macmillan. 1874.

GODIN, B. La Science sous observation- cent ans de mesure sur les scientifiques 1906 - 2006. Quebec. Lês Press de l’Université Laval. 2005.

US DEPARTMENT OF COMMERCE. Technological Innovation: its environment and management. USGPO. Washington. 1967. 